\title{
GÖTEBORGS UNIVERSITET
}

HANDELSHÖGSKOLAN

\section{WORKING PAPERS IN ECONOMICS}

No 311

\section{Swedish $\mathrm{CO}_{2}$-Emissions 1993 - 2006 - An Application of Decomposition Analysis and Some Methodological Insights}

Åsa Löfgren and Adrian Muller

January 2009

ISSN 1403-2473 (print)

ISSN 1403-2465 (online) 


\title{
Swedish $\mathrm{CO}_{2}$ Emissions 1993 - 2006 - An
}

\section{Application of Decomposition Analysis and}

\section{Some Methodological Insights}

\author{
Åsa Löfgren* and Adrian Muller ${ }^{\dagger} \ddagger$
}

ABSTRACT: This study undertakes a decomposition analysis to identify the drivers of carbon emissions change in the Swedish business and industry sectors 1993 - 2006. On aggregate, energy intensity decreased, but this does not seem to have been very important for reducing emissions. Rather, fuel substitution seems to have been more important, which is in line with findings from the decomposition literature on Sweden. However, at the sectoral level, we find no clear pattern of the effect of fuel substitution and energy intensity on emissions. We also draw some methodological conclusions: decomposition analysis should be undertaken at the most disaggregate level possible; assessing decomposition results by sum-

\footnotetext{
${ }^{*}$ Department of Economics, University of Gothenburg; e-mail: asa.lofgren@economics.gu.se

${ }^{\dagger}$ Socioeconomic Institute, University of Zürich; e-mail: adrian.mueller@soi.uzh.ch

${ }^{\ddagger}$ Financial support from Mistra’s Climate Policy Research Program (CLIPORE) is gratefully acknowledged. We thank two anonymous referees and seminar participants at the Department of Economics, University of Gothenburg, for very useful comments and are also grateful for helpful information from Anders Wadeskog at Statistics Sweden. The usual disclaimer applies.
} 
ming results over several time periods leads to biased results; and decomposition analysis should not be based only on some initial and final years of a long time period. Furthermore, we address the problem of double counting energy flows in decomposition analysis of aggregate effects when the energy sector is included, and point out potential problems related to output measured in monetary terms.

Keywords: carbon dioxide emissions; decomposition; energy intensity; fuel substitution; sectoral change;

Abbreviations: GHG: Greenhouse gas; LMDI: Logarithmic Mean Divisia Index; JEL: C02, Q40, Q54 


\section{Introduction}

From 1993 to 2006 the overall $\mathrm{CO}_{2}$ emissions in the Swedish business and industry sectors (excluding the energy sector) increased by 29\%, while their total energy input used increased by $23 \%$. Hence, in aggregate for these sectors, $\mathrm{CO}_{2}$ emissions per unit energy input increased by $5 \%$. In the same period, overall output in these sectors (measured in monetary terms) increased by $65 \%$. Thus, $\mathrm{CO}_{2}$ emissions and energy input per unit output were reduced by $22 \%$ and $26 \%$ respectively from 1993 to 2006 (aggregated over all industry and business sectors, excluding the energy sector).

The observation that energy intensity (energy input per unit output in monetary terms $)^{1}$ and emissions intensity (emissions per unit output in monetary terms) decreased on aggregate, may suggest that this pattern holds also on a more disaggregate level, i.e., for single sectors or even on the micro level (where it would reflect increased technical efficiency of processes). However, this need not be the case as other effects may be involved as well. The observed decrease in aggregate emissions intensity and energy intensity can also occur if the sectoral composition significantly changes from emissions- or energy-intensive industries to others, or as a result of relocation of emissions- or energy-intensive sectors to foreign countries or by substitution to cleaner types of energy - all without changes in energy

\footnotetext{
${ }^{1}$ Energy intensity is defined as total energy input divided by total output in monetary terms. Hence, if there is a close correlation between physical output and monetary output, this measure is a good proxy for technical energy efficiency, viz. energy input per total output in physical terms. If this correlation is low, however, the energy intensity as defined here does not capture technical energy efficiency very well. Interestingly, the decomposition literature is not aware of this potential problem (cf. the references below).
} 
intensity. Thus, judging from the aggregate development only, underlying factors cannot be identified without further analysis (cf. also Ang 1995, 2006). In addition, such a purely descriptive analysis of single factors that does not control for other influences may not correctly identify the effects of these factors on emissions.

The purpose of the present study is to disentangle and identify the most important factors explaining the overall change in $\mathrm{CO}_{2}$ emissions in the Swedish business and industry sectors for the period 1993-2006 (such as substitution between fuels, changes in emissions or energy intensity, changes in sector composition and total size of the economy). We use decomposition analysis which has proven to be a powerful tool for such research, especially when not enough data is available for econometric analysis.

A wealth of studies employ decomposition analysis to investigate the determinants of the development of green house gas emissions and the emissions intensity for different countries or country groups and for different timeperiods. Most studies investigate European countries or the EU (e.g., Torvanger 1991, Viguer 1999, Liaskas et al. 2000, Albrecht et al. 2002, Kaivo-oja and Luukkanen 2004, Cole et al. 2005, Kander and Lindmark 2006, Diakoulaki and Mandaraka 2007, Fernandez and Fernandez 2007), or Asian countries (mainly China) (e.g., Lin and Chang 1996, Ang and Choi 1997, Chung and Rhee 2001, Paul and Bhattacharya 2004, Luukkanen and Kaivo-oja 2002, Liu et al. 2007, Ma and Stern 2008). However, there are also studies on USA and Canada (Ang and Liu 2007b, Lescaroux 2008, Wing 2008), the OECD and the IEA countries (Greening et al. 1997, Unander et al. 1999, Ang and Liu 2001, Schipper et al. 2001, Hamilton and Turton 2002), and other countries (e.g., Ebohon and Ikeme 2006 for sub-saharian countries).

The results from the literature are heterogeneous, but some patterns do arise. 
First, regarding the relation of energy intensity and $\mathrm{CO}_{2}$ emissions, a rather clear difference between developed and developing countries can be noted. For the former, energy intensity decreases and contributes to lower emissions, while for the latter, increasing energy intensity contributes to higher emissions. A second, but less pronounced pattern is the difference between the years before and after the early 1990s among developed countries. There seems to have been a tendency of less reduction in energy intensity in the later years and energy intensity has correspondingly contributed less to keeping emissions from rising during this time. A third issue concerns the sectors covered. Few articles use sectoral level data, but in the articles that do, there is a trend in the manufacturing sector (in developed countries) towards lower energy intensities and a corresponding contribution to lowering emissions, while this seems to be less the case in other sectors.

Besides energy intensity, other factors clearly play a role as well. A fourth finding in the literature is that the level of economic activity is an even more important determinant of $\mathrm{CO}_{2}$ emissions than energy intensity. This is particularly pronounced in developing countries (see, e.g., Liu et al. 2007). Fifth, in many cases, structural change plays an important role. This relates to the effects described above, and some authors thus hypothesize that in their data, observed decreases in energy intensity are due to underlying sectoral changes on a lower level where no data is available (e.g., Paul and Bhattacharya 2004 for industry in India). Finally, as a sixth point, fuel substitution does usually not contribute much to lowering emissions, but can play a significant role in single cases.

Few studies focus on Sweden specifically, but some results can be found in articles that decompose carbon emissions (or carbon intensities) for several countries including Sweden (e.g. Torvanger 1991, Liaskas et al. 2000, Schipper et al. 
2001, Kaivo-oja and Luukkanen 2004, Diakoulaki and Mandaraka 2007). In most studies, both energy intensity and substitution to cleaner fuel are found to have contributed to a reduction in carbon emissions in Sweden, in particular for the period 1973-1994. Kaivo-oja and Luukkanen (2004) see no energy intensity improvement from 1990-1998, though. Similarly Diakoulaki and Mandaraka (2007), which identify a very weak effect only in 1990-1997, but a strong effect in 19972003. Notable is that substitution to cleaner fuels seems to be more important in Sweden than in other countries (Schipper et al. 2001, Kaivo-oja and Luukkanen 2004, Diakoulaki and Mandaraka 2007). This is partly due to increased use of biomass, but mainly because Swedish power generation is largely based on hydro and nuclear and massive investments in nuclear power development took place in the 1970's and 80's. It has also to be noted that in the years covered by these studies, Sweden has a relatively low emissions intensity in comparison to other countries.

Our study complements these earlier studies with new data and will reveal if the pattern of the importance of fuel substitution for reducing carbon emission prevails and if energy efficiency has continuously contributed to reduction of carbon emissions in Sweden.

A general finding when assessing the literature is that the results are sensitive to the time period chosen and the aggregation level. Results from decomposition analysis also depend on the decomposition method chosen. An ongoing discussion tries to assess the performance of the different methods according to various criteria (cf. Section 3). In this paper, we undertake a decomposition analysis using the logarithmic-mean Divisia Index method (LMDI).

The next section describes the data used and presents some first descriptive 
analysis. Then follows a short discussion of decomposition analysis and the LMDI in particular, and a description of how this method is applied to our data (Section 3). Section 4 presents and discusses the results of the analysis, and Section 5 concludes the paper.

\section{The Data}

We consider $\mathrm{CO}_{2}$ emissions from the Swedish business and industry sectors from 1993 to 2006. The data, collected by Statistics Sweden since 1993 (after a Govermental decision in 1992 based on the Government Official report SOU 1991:37) is available at www.mirdata.scb.se. The data is disaggregated into 47 subsectors/industries ${ }^{2}$ that are also listed on the web site (http://www.mirdata.scb.se/ MDInfo.aspx $\rightarrow$ Classifications $\rightarrow$ NACE). The reason the analysis does not include more recent years than 2006, is that data for those is not yet available (the next update is scheduled for 2010).

The data source differentiates between emissions from stationary and mobile sources and from process emissions. Emissions from stationary and mobile sources refer to emissions from burning various fuels, i.e., from energy generation, and process emissions are emissions resulting from a production process that are not due to energy input (e.g. $\mathrm{CO}_{2}$ emissions from the calcination in cement production: $\mathrm{CaCO}_{3}+$ heat $\rightarrow \mathrm{CaO}+\mathrm{CO}_{2}$ ). Process emissions are not included in the analysis. The dataset also includes data on ten different fuels, on electricity and district heat for all subsectors/industries (in TJ), and on production value ${ }^{3}$.

\footnotetext{
${ }^{2}$ As we focus on industry and business, we do not include the consumption of the public sector, households and NGOs which are available in the data as well.

${ }^{3}$ The production values are in year 2000 prices in SEK, but to make them more
} 
The availability of electricity and district heat as potential energy inputs in all sectors poses some problems in aggregation, as they are also outputs from the energy sector. Also, electricity can be bought on the electricity market which could further confound the results. Aggregating over all sectors including the energy sector would thus lead to double counting some of the energy input (once as fuel used by the energy sector and once as electricity or district heat used by other sectors). Unfortunately the available data does not make it possible to identify which part of the electricity and district heat used by other sectors is output from the energy sector and which part is bought on the market. We thus decided to do the aggregate analysis for all 47 business and industry sectors excluding the energy sector leaving us with 46 sectors. This problem of double counting in the energy sector does not arise in the sectoral analysis as electricity and district heat can be treated as an input, irrespective of wherefrom it originates. In addition, output and emissions from the energy sector are much more volatile over time compared to that from other sectors due to in particular shifting temperatures from year to year. Since the energy sector accounts for 20 to $30 \%$ of total emissions (depending on the year), it makes sense to exclude this sector from the aggregate analysis, as its dynamics may shadow other effects that are more relevant for the other sectors. ${ }^{4}$ A second problem for this analysis stems from the necessity to use accessible, we converted them to Euros using the exchange rate at the time of writing (March 1, 2009): 1 Euro = 12.29 SEK. Thus all monetary values reported are in million Euro.

${ }^{4}$ This can be seen by comparing the development of $\mathrm{CO}_{2}$ emissions, energy use and the decomposition analysis described below for the aggregate over 46 sectors excluding the energy sector and over all 47 sectors including the energy sector. We undertook both analyses. Due to the stated reasons, we report results for the former only. 
output measured in monetary values. Without information on prices, changes in prices may bias the results. Interestingly, this problem is not recognised in the literature. For this problem, there is unfortunately not a ready solution, as data availability restrictions and the necessity to compare different types of outputs necessitate monetarization (cf. also Footnote 1).

In the analysis, we decompose the emissions both for the aggregate level, summing over all 46 included sectors, and for the top seven subsectors in terms of emissions, i.e., pulp and paper, petroleum products, basic metals, energy, land transport (not including private cars), ship transport, and air transport separately. We identified these by choosing the sectors with the most significant contributions (each contributes more than $5 \%$ of total $\mathrm{CO}_{2}$ emissions in the Swedish business and industry sectors). In total, these seven sectors accounted for about $65 \%$ of the total Swedish $\mathrm{CO}_{2}$ emissions from 1993 to 2006. A detailed analysis of the next seven sectors in terms of emissions shares of more than 1.5\% ("next seven sectors" hereafter), was also undertaken (agriculture, forestry, food/beverage/tobacco, chemicals, non-metallic mineral products, construction, wholesale and retail trade) but the results are not presented in detail as they are largely similar to the results for the first seven sectors (some differences are reported separately in the discussion in Section 4). These 14 sectors together account for about $90 \%$ of total carbon emissions.

Figure 1 depicts how total $\mathrm{CO}_{2}$ emissions have evolved over time in the Swedish business and industry sectors (excluding the energy sector). As can be seen, they have increased by $29 \%$ over the studied period.

Total output increased by almost $65 \%$ over the same period, and total energy input increased by $23 \%$ (see Figure 2). 


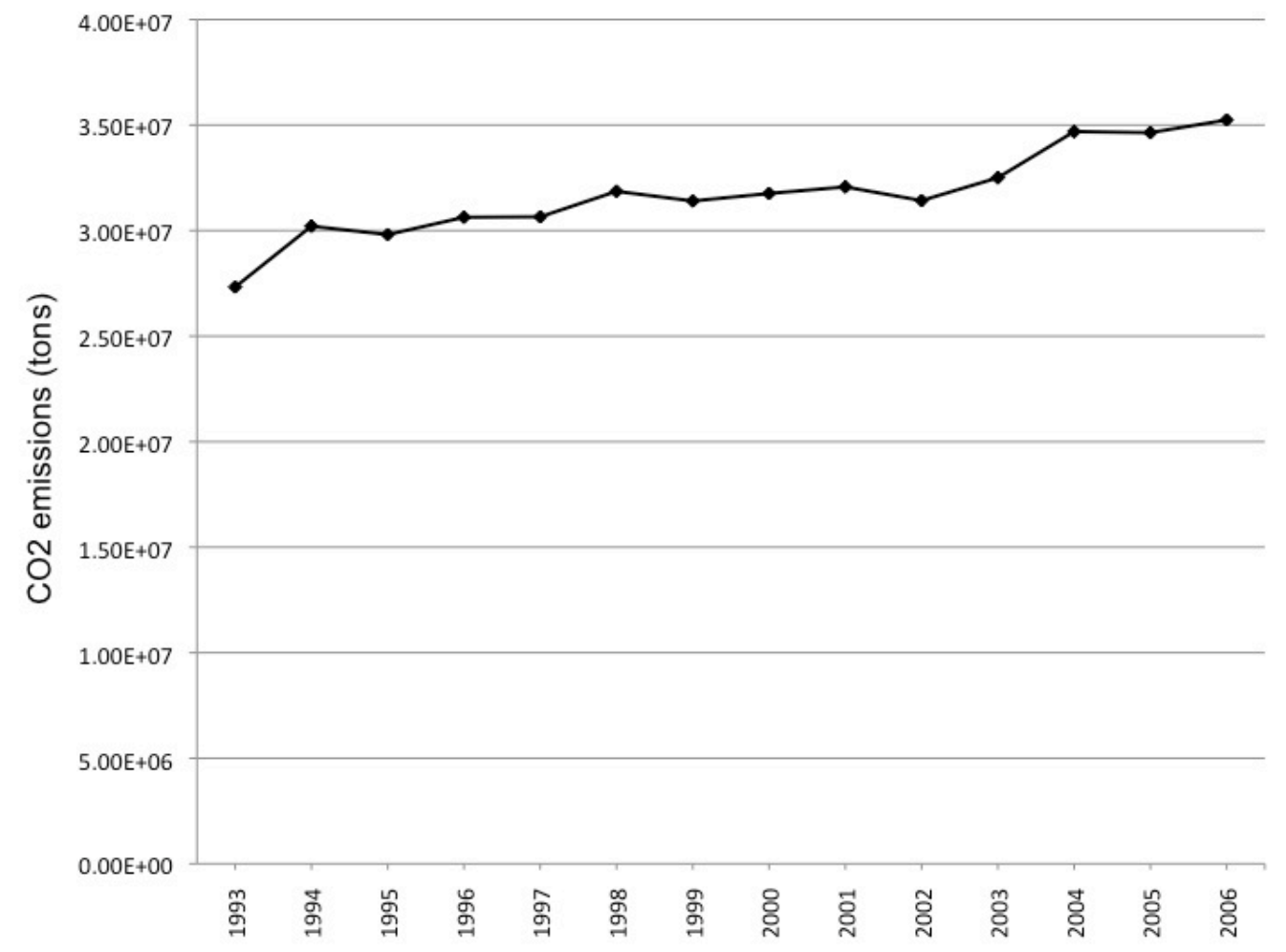

Figure 1: Total $\mathrm{CO}_{2}$ emissions (46 sectors, not including the energy sector)

In connection to the development of these basic variables, $\mathrm{CO}_{2}$ emissions per unit energy input increased by approximately $5 \%$, and $\mathrm{CO}_{2}$ emissions and energy input per unit output value, aggregated over all sectors (excluding the energy sector), significantly decreased by $22 \%$ and $26 \%$ respectively. Overall emissions intensity and energy intensity thus decreased significantly (Figure 3).

As the carbon content of a specific fuel type does not change over time, variations in $\mathrm{CO}_{2}$ emissions per unit energy input are due to changes in the fuel mix. For example, using biofuels instead of fossil fuels results in reduced $\mathrm{CO}_{2}$ emissions per unit energy, as biofuels, which are assumed to be renewable, are counted with zero emissions. 


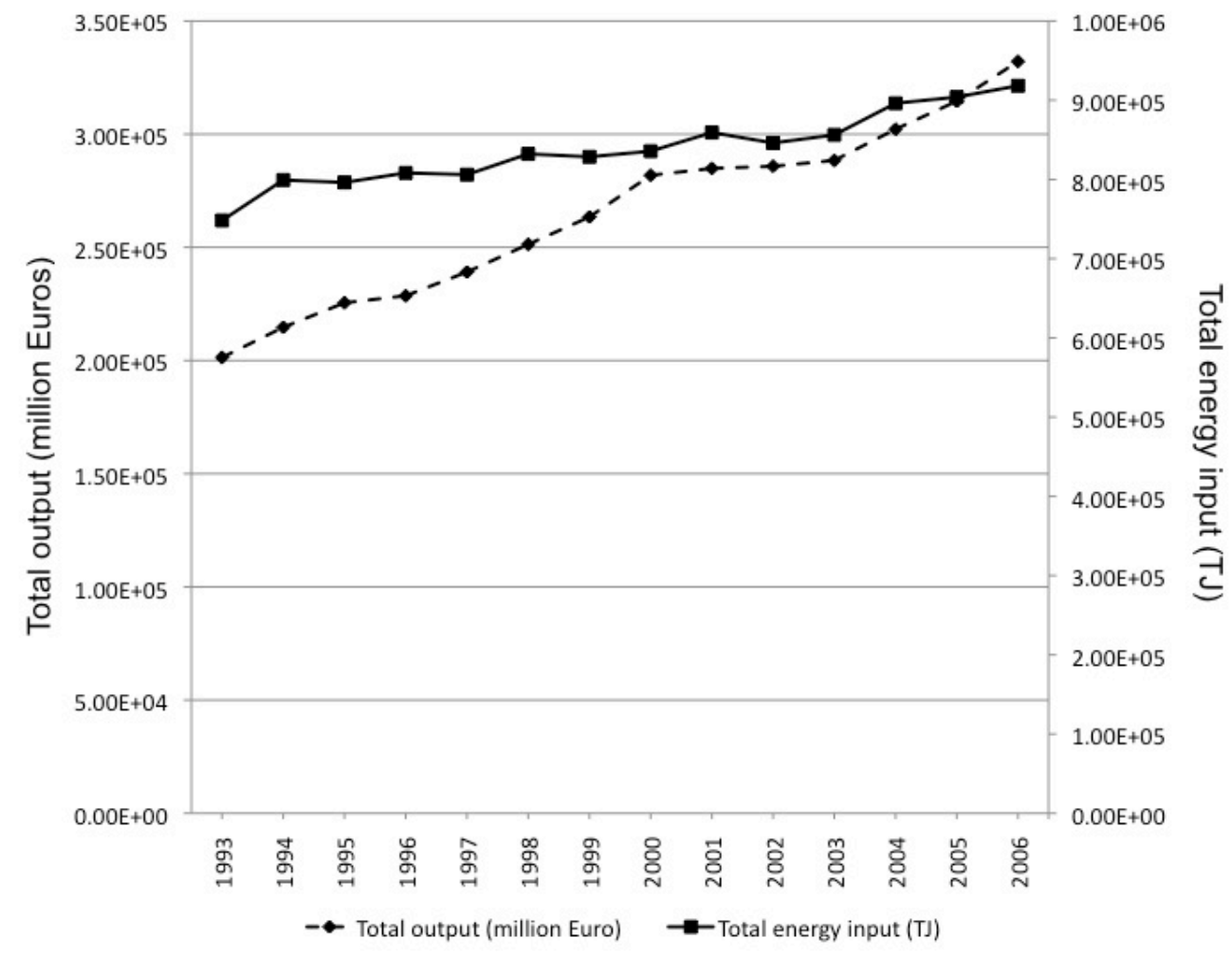

Figure 2: Total output (left) and total energy input (right) (46 sectors, not including the energy sector)

We also looked at the development of the same variables for each of the top seven sectors identified above separately. There, no clear patterns emerge how the respective variables of interest developed. ${ }^{5} \mathrm{CO}_{2}$ emissions and energy input varied quite substantially for some sectors, in particular for the energy sector, while output increased for all sectors. One reason for the variation of emissions and energy input in the energy sector is changes in weather conditions. Emissions and energy use increase in cold years since the marginal production of electricity in Sweden is fossil-fuel based and a significant part of heating is electric (e.g. 1996

\footnotetext{
${ }^{5}$ The sector-wise data is available from the authors on request.
} 


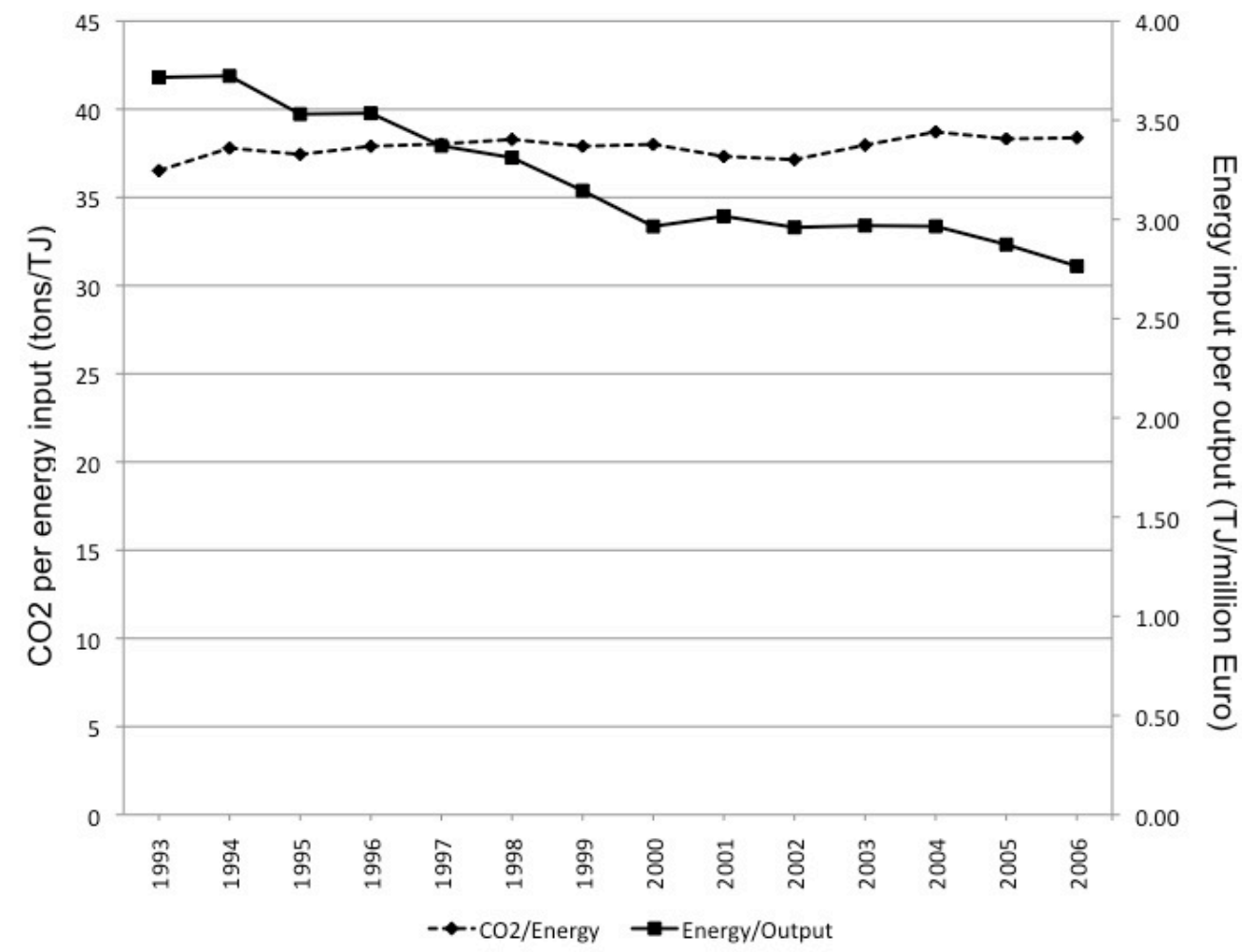

Figure 3: $\mathrm{CO}_{2}$ per unit energy input (left) and energy input per unit output value (right) (46 sectors, not including the energy sector)

was a particurlarly cold year and 2000 a particularly warm year, EPA 2009). We point out that the energy sector together with the pulp and paper sector are the only two of the seven most emitting sectors that show a reduction in total $\mathrm{CO}_{2}$ emissions (among the next seven sectors, only the food/beverage/tobacco sector reduced its emissions).

Also, there is no clear trend for the development of energy intensity in the top seven sectors. This is most notable for the energy sector. However, ship transport shows a clear trend of increasing energy intensity over time. Similarly, but to a lesser extent, the energy intensity increased in the air transport sector as 
well. A decrease in energy intensity can only be identified for pulp and paper and basic metal (for the next seven sectors, all except forestry show decreasing energy intensity).

Emissions per unit energy input also vary over time and among sectors. This is a result of sectors substituting between different fuels differently. A reduction of emissions per unit of energy input can predominantly be observed in energy, pulp and paper, and, toward the end of the period, in the petroleum products sector. It has to be emphasized that while fuel substitution to electricity or district heat does drive down emissions per unit energy input (emissions from electricity and district heat are counted as zero in the data), it does not necessarily result in a corresponding reduction in emissions globally, as those may arise elsewhere depending on how the electricity or heat used was generated. In particular, the significant reduction in emissions per unit energy input in the energy sector is likely due to the significant increase in district heat input that ocurred in 2005 and 2006 (cf. Footnote 6 below).

In the following, we undertake a decomposition analysis to identify the effects of energy intensity and other factors on $\mathrm{CO}_{2}$ emissions. This method, its relation to other methods that could be applied, and the result of its application to the data described in this section are discussed in Sections 3 and 4.

\section{Method}

First, we list the variables used in the rest of the paper (Table 1):

Insert Table 1 here

Next, we introduce the formalism of decomposition. We use the case we are 
interested in as an example. Total $\mathrm{CO}_{2}$ emissions from industry, $\mathrm{CO} 2$, can be written as the following (tautological) product:

$$
C O 2=\sum_{i} C O 2_{i}=\sum_{i} \frac{C O 2_{i}}{E_{i}} \frac{E_{i}}{Y_{i}} \frac{Y_{i}}{Y} Y=: \sum_{i} f_{i} I_{i} y_{i} Y,
$$

The decomposition of the change in the emission level $\mathrm{CO}_{2}$ from time period $t$ to period $t+1$ into different contributions is given by the following equation (cf. Muller 2008 for some general discussion):

$$
\begin{aligned}
& \Delta C O 2_{t+1, t}:=C O 2(t+1)-C(t)=\int_{t}^{t+1} \frac{d C O 2}{d \tau} d \tau \\
= & \sum_{i} \int_{t}^{t+1}\left(I_{i} y_{i} Y \frac{d f_{i}}{d \tau}+f_{i} y_{i} Y \frac{d I_{i}}{d \tau}+f_{i} I_{i} Y \frac{d y_{i}}{d \tau}+f_{i} I_{i} y_{i} \frac{d Y}{d \tau}\right) d \tau \\
= & : \Delta f_{t+1, t}+\Delta I_{t+1, t}+\Delta y_{t+1, t}+\Delta Y_{t+1, t} .
\end{aligned}
$$

Here the change in emissions from $t$ to $t+1$ is decomposed into four parts that refer to fuel emission factors (the $f$-term, capturing changes in fuelmix, as described in the previous section), energy intensity (the $I$-term), industrial structure (the $y$-term), and overall industrial activity or size (the $Y$-term). The interpretation of this decomposition is as follows: Each term captures how much of the change in $\mathrm{CO}_{2}$ emissions during the years observed can be assigned to changes in the respective variable. The magnitude of these contributions thus determines the effect of changes in the respective variables, given nothing else would have changed.

The effect of changes in emissions per energy input $(\Delta f)$ captures the changes in shares of different fuels (with constant emissions coefficients) in relation to total sector energy input. If the share of, for instance, coal increased while that 
of natural gas decreased compared to the year before, then $\Delta f$ will be positive, as coal emits more $\mathrm{CO}_{2}$ per unit energy generated than natural gas. The energy intensity effect $(\Delta I)$ captures the reduction in emitted $\mathrm{CO}_{2}$ due to decreased energy intensity, e.g., due to the use of more energy efficient technology (less energy consumption per unit of production). The structural effect $(\Delta y)$ captures changes in the relative sizes of sectors. For example, if sectors that emit relatively little $\mathrm{CO}_{2}$ increase their share of the total production value, there will be a reduction of total emitted $\mathrm{CO}_{2}$ in relation to production, and hence this term will be negative. Finally, the production term $(\Delta Y)$ captures emission changes due to changes in total production value. An increase in production will all else equal yield a positive term.

Although equation (2) is exact, the data necessary to calculate the exact integrals is never available. Usually, the quantities involved are only known for discrete points $t$ and $t+1$, e.g., for subsequent years, while the exact shape of the function describing these quantities between these points is unknown. Consequently, the integrals in (2) have to be approximated. We thus face the problem of approximating terms of the following structure (equation (3)), where the integrand is only known for the boundary values of the integration interval. Even worse, the derivatives involved are not known at all, not even for the boundaries (the underlying functions are known for the boundaries, though).

$$
\Delta f_{t+1, t}=\sum_{i} \int_{t}^{t+1} I_{i} y_{i} Y \frac{d f_{i}}{d \tau} d \tau
$$

There are several methods to approximate these integrals and derivatives given knowledge about the functions on the boundaries only. The different existing 
decomposition methods can be understood as different approaches to implement such approximations (cf. Muller 2007, 2008 for an overview). Hence, results of decomposition analyses are often dependent on the method chosen (e.g., Ang 1995, Greening et al. 1997, Ang 2004, Ang and Liu 2007c). On the other hand, results from different methods can also be very similar. For some cases, it can be shown that this is due to analytical equivalence of the methods (e.g., Choi and Ang 2003, Ang and Liu 2007c). For surveys on decomposition methods and their application to emissions, energy use and intensity, see Ang (1995) and Liu and Ang (2007). The logarithmic mean Divisia index (LMDI) approach is currently seen as one of the most favorable decomposition methods (Ang 2004, Ang and Liu 2001, 2007a and b, Liu and Ang 2007). This is due to its advantageous properties regarding several analytical criteria. One of the most important properties is the absence of any residual term; that is, the decomposition calculated according to the LMDI is complete without any contribution that is not attributed to the key variables that the decomposition is based on. The importance of a zero residual as a decisive criterion for the performance of a decomposition method is contested, though (Muller 2008). This is due to the fact that a good approximation need not necessarily have a zero residual and that a zero residual can also be realised for a bad approximation (e.g., if contributions are wrongly assigned to key variables but in such a way that no residual remains). However, also in the light of this criticism, the LMDI still seems to be one of the best decomposition methods available (Muller 2007). We therefore decided to employ the LMDI for the decomposition analysis presented here.

The LMDI is defined via the "logarithmic mean function" $L(x, y):=\frac{x-y}{\ln (x)-\ln (y)}$, and the various contributions $\Delta X_{t+1, t}$ then take the following form: 


$$
\Delta f_{t+1, t}^{L M D I}:=\sum_{i} L\left(f_{i} I_{i} y_{i} Y(t+1), f_{i} I_{i} y_{i} Y(t)\right) \ln \left(\frac{f_{i}(t+1)}{f_{i}(t)}\right),
$$

and correspondingly for $\Delta I_{t+1, t}^{L M D I}, \Delta y_{t+1, t}^{L M D I}$ and $\Delta Y_{t+1, t}^{L M D I}$. We also undertake sector-wise analysis that correspondingly is based on a shorter form of equation (1), namely $C O 2_{i}=\frac{C O 2_{i}}{E_{i}} \frac{E_{i}}{Y_{i}} Y_{i}=: \sum_{i} f_{i} I_{i} y_{i}$, for each sector $i$.

It is important to emphasize that decomposition analysis is a descriptive method only wherefrom no conclusion for future development may be inferred, as it does not involve any statistical estimation of relevant parameters. The advantage of such a decomposition analysis is that it gives a detailed and transparent assessment of key drivers underlying past development of emissions, based on very sparse assumptions only. For example, it can reveal effects of structural breaks in the data, such as in long time series on energy intensity, where different policies may lead to breaks in the development of this variable. However, there is also a disadvantage: due to the sparse assumptions made and the descriptive character of the method, no statistical inference is possible. This method thus transparently informs the discussion on past development with corresponding indications on what may and what not may be important in the future as well. But it cannot establish causal relationships. It is best complemented with some statistical analysis that allows for inference, such as regression analysis given that the necessary data is available. This brings us to another advantage of decomposition analysis, namely its low data requirement. Decomposition analysis is possible also in cases where too few data points for a regression are available. Due to the very different characters of decomposition analysis and regression-based methods, neither one can replace the other; rather, each may provide a relevant contribution to an overall understand- 
ing of the past and future development of emissions. Finally, we emphasize again that the decomposition results can be sensitive to the level of aggregation (cf. Ang 1995, 2006) and to price changes if output is measured in monetary values, as is usually done in decomposition analysis (cf. Footnote 1).

\section{Results and Discussion}

Figures A1 and A2a-A2g in the Appendix present the decomposition results for each annual period from 1993 to 2006 for the seven Swedish sectors with the highest $\mathrm{CO}_{2}$ emissions. The results from the next seven sectors are largely similar, and we only occasionally report those where differences are important (the results are available from the authors upon request). Since the results can be quite cumbersome to analyze, we summarize them in Table 2 below. Table 2 captures the overall trends from 1993 to 2006 by sector (based on the analysis of each annual period, cf. also Figures A1 and A2a-A2g; the table caption gives further details on how to read this table). Table 2 also includes the summary results for the next seven sectors.

We chose the presentation of decomposition results given in Table 2, as we want to emphasize that summing the effects of one factor over all years usually does not reveal a reliable overall effect of the factor in question. If a certain factor shows, for example, a pattern of several positive and negative contributions to emissions that more or less cancel in sum, the assessment may change dramatically if additional years are included. To illustrate this, we summed the effects of the different contributions from 1993 to 2004 and to 2006 respectively, and arrived at very different conclusions in the cases where no clear positive or negative trend in terms of contributions to emissions could be identified (e.g., energy intensity in 
the energy sector, cf. also Figure A2d). The entries in Table 2 account for this, as for this case (energy intensity in the energy sector), for example, it reads " \pm ", thus indicating this indeterminacy of effects over the whole period (cf. the table caption for further details). For the interested reader, the summary results for the whole period (both total and by sector) are provided in Table A2 and A3 in the Appendix, for both the periods 1993-2004 and 1993-2006. This illustrates in detail how a somewhat longer or shorter period has strong effects on the aggregate results for many sectors and factors. Decomposition analysis should thus use as many intermediate time-intervals as possible, and results from decomposition analysis of changes over several years based on the first and last year only or reporting sums over all years (or average values) should be used very cautiously (both is frequently reported in the literature, though, see e.g., Torvanger 1991, Liaskas et al. 2000, Schipper et al. 2001, Albrecht et al. 2002, Hamilton and Turton 2002, Diakoulaki and Mandaraka 2007).

Insert Table 2 here

We now discuss the results presented in Table 2 and in the Appendix (Figures $\mathrm{A} 1$ and $\mathrm{A} 2 \mathrm{a}-\mathrm{A} 2 \mathrm{~g}$ ), and contrast them with the patterns and hypotheses identified in the literature (cf. Table A1). We first note that the decomposition results do not show a clear trend of decreasing energy intensity and corresponding effects of changes in energy intensity on emissions in the seven most emitting sectors. Most notably, there is no general decrease in $\mathrm{CO}_{2}$ emissions due to energy intensity for the energy sector. For air and ship transport, increasing energy intensity contributed to higher emissions, while decreasing energy intensity lowered emissions in the pulp and paper and the basic metals sector. Similarly, in the next seven sectors, the effect of energy intensity contributed to decreased emissions in two 
sectors only (wholesale and retail trade, and food/beverage/tobacco), while for the others, the effect is neither clearly positive nor negative (except for forestry where an increasing energy intensity increased emissions).

Next, the decomposition analysis reveals a decreasing effect of fuel substitution on emissions, both on aggregate and for some sectors. In particular, the effect of fuel substitution contributed to a reduction of $\mathrm{CO}_{2}$ emissions for energy ${ }^{6}$, pulp and paper, and petroleum products and remained indefinite for the other sectors. Fuel substitution increased emissions, though, if we look at the decomposition results for the next seven sectors (an increasing effect for wholesale and retail trade, chemicals, and forestry; slightly decreasing for agriculture and food/beverage/tobacco; and without definite effects for the others).

These results differ partly from the findings in the literature that employs decomposition analysis (cf. Section 1). In contrast to most of the literature, on aggregate, we find no support for decreased energy intensity leading to reduced emissions. However, earlier studies on Sweden indicate that energy intensity is relatively of less importance for Sweden compared to other countries. We also analyse the years 1993 onwards, i.e. the period for which energy intensity is judged to be less important in the literature. Corroborating findings from the specific literature on Sweden, we find that fuel substitution seems important in Sweden. This is generally not found in the literature on other countries, where

\footnotetext{
${ }^{6}$ Note that the significant increase in district heating in 2005 and 2006 in the energy sector results in a large contribution from fuel substitution on reducing emissions (district heating counts as zero emissions). However, we are not sure of the origin of this huge increase in district heating use. We are currently investigating this issue, and before this is resolved caution should be taken when interpreting the large effect during these two years.
} 
fuel substitution often plays a minor role only. On the other hand, similar to the literature, we clearly see both a contribution to increasing emissions from increased output and the importance of sectoral change (production increased in less $\mathrm{CO}_{2}$ intensive sectors in relation to total production) for emission reductions on aggregate.

As can be seen from the differences between the aggregate and sector-wise results, undertaking the analysis on a disaggregated level, both sector-wise and regarding time periods, clearly adds information. In our case however, disaggregation does not change two of the important general results for the seven most emitting sectors: low importance of energy intensity changes for emissions reductions and a tendency of fuel substitution leading to emissions reductions. Further disaggregation to sub-sector levels would clearly be informative, but in our case, this is not possible due to lack of data.

\section{Conclusions}

The decomposition analysis of the $\mathrm{CO}_{2}$ emissions from the Swedish industry and business sectors undertaken in this article leads to several conclusions. In contrast to the findings in the general literature, and for Sweden during the period 19731994, decreasing energy intensity was not very important for reducing emissions in 1993-2006 in Sweden. The discrepancy to the literature on the earlier years is mitigated by the literature finding that the energy intensity contributes less to reduced emissions after the early 1990's than before. It would thus be important to further investigate reasons why energy intensity did not contribute to lower emissions after the early 1990's and which policy measures may be used to support such contribution in the future. It has to be noted that Sweden had already reached 
a comparably low level of emissions intensity by the early 1990's and that it has a high share of hydro and nuclear power production (Schipper et al. 2001).

On the other hand, fuel substitution, which is generally seen as less influential in general but important for Sweden, seems to have continuously played a more important role for reduction of carbon emissions in Sweden. However, no clear overall pattern regarding the importance of energy intensity and fuel substitution for reduced emissions arises when a sectoral analysis is undertaken, although effects can be identified for individual sectors. Further investigation of the contributions of fuel substitution should focus on whether they stem from switches to renewables such as biomass or rather from switches to electricity used, which is largely based on hydro and nuclear power generation in Sweden. As stated in the literature, we find that sectoral composition plays an important role for emissions on aggregate, and production increase is an important driver of increased emissions, both sectorwise and on aggregate.

We draw some methodological conclusions as well. As reported in the literature, we find that undertaking decomposition analysis on levels as disaggregate as possible is necessary to arrive at a more complete picture. In addition, the time period chosen may significantly influence results if overall changes over several time periods are assessed by summing decomposition results from each period. Similarly, decomposition based on the first and last period of a longer time span may lead to wrong results. Thus, also regarding time, decomposition analysis as disaggregate as possible needs to be undertaken to not bias results. Although frequently used in the literature, results from decomposition analysis based on the first and last year of a longer period only or based on summation or averaging of several annual decompositions should be used very cautiously only. In this light, consensus 
or discrepancy with findings from the literature are not necessarily meaningful.

We also encountered two specific problems of decomposition analysis. First, the presence of the energy sector may lead to double counting of some energy flows. The aggregate analysis needs to account for this and the energy sector thus needs to be treated separately if further information to avoid double counting is missing. This can however be done and does not pose further problems. It even has the advantage that for the aggregate analysis, specific patterns from the energy sector do not shadow patterns that are more relevant for other sectors. A second problem arises if output is measured in monetary values because then changes in prices may bias the results from decomposition analysis. Further research on how sensitive different decomposition methods are to this effect and how large such a bias may be is necessary in order to assess the reliability of decomposition analysis that employs output measured in monetary values. However, employing output in monetary values can often not be avoided due to data availability and problems of comparability.

Finally, it is interesting to shortly link our findings to the prevailing regulatory context. Regarding regulatory burden, the most emitting sectors in Sweden can be divided into three groups: (1) the land transport sector, which is highly taxed; (2) the industry sectors (pulp and paper, petroleum products, basic metals) and the energy sector, which are partly exempted from taxes but subject to other regulations, such as the EU Emissions Trading Scheme; (3) air and ship transport, which are almost completely exempted from taxes and other climate policy instruments. Also notable is the fact that the regulatory pressure to decrease $\mathrm{CO}_{2}$ emissions has increased over time. ${ }^{7}$ Since 2003 in particular, there have been

\footnotetext{
${ }^{7}$ Regulation of $\mathrm{CO}_{2}$ emissions occurs via a bundle of different policy instruments. Most important are the energy and $\mathrm{CO}_{2}$ taxes. Although used in some cases for
} 
several additional policy instruments targeting $\mathrm{CO}_{2}$ emissions from the industry sectors (pulp and paper, petroleum products, basic metals) and the energy sector. It is interesting to see that although land transport is heavily taxed, this sector does not show large effects of substitution to cleaner fuels and decreased energy intensity, which we believe is an interesting area for future research. Neither do we see any clear increase in emissions reductions after 2003, which might have been expected due to the increasing regulatory burdens since 2003. As one may expect from the low regulatory level, though, air and ship transport show no tendency of reduced emissions. Increased energy intensity even led to increased emissions, and no emissions reductions due to fuel substitution to cleaner fuels took place. For a reliable analysis of how a certain policy instrument actually influences emissions for specific sectors, more detailed and richer data would be necessary and decomposition analysis should be complemented with regression based methods.

decades before, broad general coverage of the energy tax was introduced in 1957 . The $\mathrm{CO}_{2}$ tax was introduced in 1991. Over the years, the carbon tax share of the fuel tax has been increased and has grown more important relative to the energy tax. The current tax law (the Law on Tax on Energy, LSE) has been in effect since 1995. Apart from taxes, some other policy instruments broadly targeting $\mathrm{CO}_{2}$ emissions were also used in Sweden from 1993 to 2006, i.e., the Local Investment Program (LIP), which was in effect 1998-2002; the Climate Investment Program (KLIMP), which started in 2003; support of energy efficient technology and green electricity certificates which started in 2003; and the EU emissions trading scheme (EU-ETS) which started in 2005. Details on the regulatory context in Sweden can be found in LSE (1994) and on the web-site of the Swedish Environmental Protection Agency, http://www.swedishepa.se/en/In-English/Menu. 


\section{Appendix}

a) General literature

1: on aggregate, decreasing energy intensity contributes to lower emissions in developed countries

2: this effect was larger before the early 1990's than after

3: the effect of decreasing energy intensity is larger in the manufacturing sector than in other sectors

4: increasing output usually has a large effect on increasing emissions

5: sectoral change is important (i.e. aggregate reduction in emissions intensity can be due to sectoral change)

6: there is no general pattern that fuel substitution contributes to reducing emissions

b) Specific literature on Sweden

1: decreasing emissions intensity and substitution to cleaner fuels contributed to decreasing emissions in 1973-1994

2: the effect of substitution to cleaner fuels to reduce $\mathrm{CO}_{2}$ emissions played a role in particular in 1973-1994 and it is more important in Sweden than in other countries

Table A 1: Hypotheses and patterns identified in the literature (see Section 1)

Figures A1, A2a-A2g: at the end of the document. 


\begin{tabular}{|c|c|c|c|c|}
\hline \multirow{2}{*}{$\begin{array}{l}\text { sector } \\
\text { first line: 1993-2006 } \\
\text { second line: 1993-2004 }\end{array}$} & \multicolumn{3}{|c|}{ Change in em. due to changes in: } & \multirow[b]{2}{*}{ total $\mathrm{CO}_{2}$ change } \\
\hline & fuel subst. & en. int. & prod. & \\
\hline \multirow[t]{2}{*}{ Pulp and paper } & $-169 \%$ & $-139 \%$ & $+208 \%$ & $-300 ’ 000$ \\
\hline & $-346 \%$ & $-565 \%$ & $-811 \%$ & $-70 ’ 000$ \\
\hline \multirow[t]{2}{*}{ Petroleum } & $-35 \%$ & $-30 \%$ & $+165 \%$ & $+406^{\prime} 000$ \\
\hline & $-22 \%$ & $+25 \%$ & $+97 \%$ & $+373^{\prime} 000$ \\
\hline \multirow[t]{2}{*}{ Basic metal } & $-186 \%$ & $-1080 \%$ & $+1366 \%$ & $+73^{\prime} 000$ \\
\hline & $+13 \%$ & $-43 \%$ & $+130 \%$ & $+711^{\prime} 000$ \\
\hline \multirow[t]{2}{*}{ Energy and heating } & $-245 \%$ & $+86 \%$ & $+59 \%$ & $-1^{\prime} 912 ' 000$ \\
\hline & $-2186 \%$ & $+564 \%$ & $+1522 \%$ & $-94^{\prime} 000$ \\
\hline \multirow[t]{2}{*}{ Landtransport } & $-11 \%$ & $-151 \%$ & $+262 \%$ & $+336^{\prime} 000$ \\
\hline & $-31 \%$ & $-148 \%$ & $+279 \%$ & $+251^{\prime} 000$ \\
\hline \multirow[t]{2}{*}{ Shipping } & $+1 \%$ & $+64 \%$ & $+35 \%$ & $+3^{\prime} 750^{\prime} 000$ \\
\hline & $+1 \%$ & $+78 \%$ & $+21 \%$ & $+4^{\prime} 305^{\prime} 000$ \\
\hline \multirow[t]{2}{*}{ Aviation } & $+0 \%$ & $+42 \%$ & $+58 \%$ & $+818^{\prime} 000$ \\
\hline & $+1 \%$ & $+53 \%$ & $+46 \%$ & $+627^{\prime} 000$ \\
\hline
\end{tabular}

Table A 2: Summary of decomposition results by sector, 1993-2006 (first line) and 1993-2004 (second line) (sign and percentage contribution to total sector-wise change from each factor) 


\begin{tabular}{|c|c|c|c|c|c|}
\hline \multirow{5}{*}{ period } & \multicolumn{4}{c|}{ Change in $\mathrm{CO}_{2}$ emissions due to changes in: } & \multicolumn{1}{c|}{} \\
\cline { 2 - 5 } & fuel subst, en. eff. sector structure & \multicolumn{1}{c|}{ prod. } & \multicolumn{1}{c|}{ total $\mathrm{CO}_{2}$ change } \\
\hline $1993-2006$ & $-14 \%$ & $-20 \%$ & $-66 \%$ & $+200 \%$ & $+7^{\prime} 9166^{\prime} 000$ \\
$1993-2004$ & $-6 \%$ & $-2 \%$ & $-63 \%$ & $+171 \%$ & $+7^{\prime} 365 ' 000$ \\
\hline
\end{tabular}

Table A 3: Summary of decomposition results for all 46 sectors (excluding the energy sector), 1993-2006 and 1993-2004

\section{References}

Albrecht, J., Fran@is, D. and Schoors, K. (2002). A Shapley decomposition of carbon emissions without residuals, Energy Policy, 39, pp.727-736

Ang, B.W. (1995). Decomposition Methodology in Industrial Energy Demand Analysis, Energy, 20(11), pp.1081-1095.

Ang, B.W. (2004). Decomposition analysis for policymaking in energy: which is the preferred method?, Energy Policy, 32, pp.1131-1139.

Ang, B.W. (2006). Monitoring changes in economy-wide energy efficiency: From energy GDP ratio to composite efficiency index, Energy Policy, 34, pp. 574-582.

Ang, B.W. and Ki-Hong Choi (1997). Decomposition of Aggregate Energy and Gas Emission Intensities for Industry: A Refined Divisia Index Method, The Energy Journal, 18(3), pp.59-73. 
Ang, B.W., Liu, N. (2001). A new energy decomposition method: perfect in decomposition and consistent in aggregation, Energy, 26, pp.537-548.

Ang, B.W., Liu, N. (2007a). Handling zero values in the logarithmic mean Divisia index decomposition approach, Energy Policy, 35(1), pp.238-246.

Ang, B.W., Liu, N. (2007b). Negative value problems of the logarithmic mean Divisia index decomposition approach, Energy Policy, 35(1), pp.739742.

Ang, B.W., Liu, N. (2007c). Energy decomposition analysis: IEA model versus other methods, Energy Policy, 35(5), pp.1426-1432.

Choi, K.H., Ang, B.W. (2003). Decomposition of aggregate energy intensity changes in two measures: ratio and difference, Energy Economics, 25(6), pp.615-624.

Chung, H., Rhee, H. (2001). A residual-free decomposition of the sources of carbon dioxide emissions: a case of the Korean Industries, Energy, 26, pp.15-30.

Cole, M.A., Elliot, R.J.R. and Shimamoto, K. (2005). A Note on Trends in European Industrial Pollution Intensities: A Divisia Index Approach, The Energy Journal, 26(3), pp.61-73. 
Diakoulaki, D. and Mandaraka, M. (2007). Decomposition analysis for assessing the progress in decoupling industrial growth from CO2 emissions in the EU manufacturing sector, Energy Economics, 29, pp.636-664.

Ebohon, O.J. and Ikeme, A.J. (2006). Decomposition analysis of CO2 emission intensity between oilproducing and non-oil-producing sub-Saharan African countries, Energy Policy, 34, pp.3599-3611.

EPA 2009. Average Daily Temperature Archive, The University of Dayton and the US Environmental Protection Agency EPA, http://www. engr. udayton. edu/weather/default.htm (accessed 27.3.2009).

Fernandez, E., Fernandez, P. (2007). An extension to Sun's decomposition methodology: The Path Based approach, Energy Economics, 30, pp.1020-1036.

Greening, L.A., Davis, W.B., Schipper, L. and Khrushch, M. (1997). Comparison of six decomposition methods: application to aggregate energy intensity for manufacturing in 10 OECD countries, Energy Economics, 19, pp.375-390.

Hamilton, C. and Turton, H. (2002). Determinants of emissions growth in OECD countries, Energy Policy, 30, pp.63-71. 
Kaivo-oja, J. and Luukkanen, J. (2004). The European Union balancing between $\mathrm{CO} 2$ reduction commitments and growth policies: decomposition analyses, Energy Policy, 32, pp1511-1530.

Kander, A. and Lindmark, M. (2006). Foreign trade and declining pollution in Sweden: a decomposition analysis of long-term structural and technological effects, Energy Policy, 34, pp.1590-1599.

Lescaroux, F. (2008). Decomposition of US manufacturing energy intensity and elasticities of components with respect to energy prices, Energy Economics, 30, pp.1068-1080.

Liaskas, K., Mavrotas, G., Mandaraka, M. and Diakoulaki, D. (2000). Decomposition of industrial $\mathrm{CO}_{2}$ emissions: The case of European Union, Energy Economics, 22, pp.383-394.

Lin X. Q. and Chang, T. C. (1996). Decomposition of SO2, NOx and CO2 Emissions from Energy Use of Major Economic Sectors in Taiwan, The Energy Journal, 17(1), pp.1-17.

Liu, N., Ang, B.W. (2007). Factors shaping aggregate energy intensity trend for industry: Energy intensity versus product mix, Energy Economics, 29, pp.609-635.

Liu, L.-C., Fan,Y., Wu,G., and Wei, Y.-M. (2007). Using LMDI method 
to analyze the change of China's industrial CO2 emissions from final fuel use: An empirical analysis, Energy Policy, 35, pp.5892-5900.

LSE (1994). Lagen om skatt på energi (1994:1776; the Swedish energy tax law. http://www.notisum.se/rnp/sls/lag/19941776.htm (accessed 27.3.2009)

Luukkanen, J. and Kaivo-oja, J. (2002). ASEAN tigers and sustainability of energy use - decomposition analysis of energy and $\mathrm{CO}_{2}$ efficiency dynamics, Energy Policy, 30, pp.281-292.

Ma, C. and Stern, D.I. (2008). China's changing energy intensity trend: A decomposition analysis, Energy Economics, 30, pp.1037-1053.

Muller, A. (2008). Clarifying Poverty Decomposition, Scandinavian Working Papers in Economics 217.

Muller, A. (2007). Putting decomposition of energy use and pollution on a firm footing - clarifications on the residual, zero and negative values and strategies to assess the performance of decomposition methods, Scandinavian Working Papers in Economics 215.

Paul, S. and Bhattacharya, R.N. (2004). CO2 emission from energy use in India: a decomposition analysis, Energy Policy, 32, pp.585-593

Schipper, L., Murtishaw, S., Khrushch, M., Ting, M., Karbuz, S. and 
Unander, F. (2001). Carbon emissions from manufacturing energy use in 13 IEA countries: long-term trends through 1995, Energy Policy, 29, pp.667688.

Torvanger, A. (1991). Manufacturing Sector Carbon Dioxide Emissions in Nine OECD Countries, 1973-1987, Energy Economics, 13(3), pp.168-186.

Unander, F. Karbuz, S., Schipper, L., Khrushch, M. and Ting, M. (1999). Manufacturing energy use in OECD countries: decomposition of long-term trends, Energy Policy, 27, pp.769-778.

Viguier, L. (1999). Emissions of $\mathrm{SO}_{2}, \mathrm{NO}_{x}$ and $\mathrm{CO}_{2}$ in Transition Economies: Emission Inventories and Divisia Index Analysis, The Energy Journal, 20(2), pp.59-87.

Wing, I.S. (2008). Explaining the declining energy intensity of the U.S. economy, Resource and Energy Economics, 30, pp 21-49.

\section{List of Tables and Table Captions}




\begin{tabular}{|l|l|}
\hline$E_{i}$ & total energy consumption in sector $i$ \\
$E$ & total energy consumption $\left(E=\sum_{i} E_{i}\right)$ \\
$Y_{i}$ & value of production in sector $i$ \\
$Y$ & total value of production $\left(Y=\sum_{i} Y_{i}\right)$ \\
$y_{i}$ & production share of sector $i\left(y_{i}=Y_{i} / Y\right)$ \\
$I_{i}$ & energy intensity of sector $i\left(I_{i}=E_{i} / Y_{i}\right)$ \\
$C O 2_{i}$ & $C O_{2}$ emissions arising from fossil fuel consumption in sector $i$ \\
$C O 2$ & total $C O_{2}$ emissions arising from fossil fuel consumption \\
& $\left(C O 2=\sum_{i} C O 2_{i}\right)$ \\
$f_{i}$ & emission coefficient of energy use in sector $i\left(C O 2_{i} / E_{i}\right)$ \\
\hline
\end{tabular}

Table 1: The variables used for the decomposition analysis

In the following figures $\mathrm{A} 1, \mathrm{~A} 2 \mathrm{a}-\mathrm{A} 2 \mathrm{~g}$, the last columns depict the sum of the effects over all years, scaled by $1 / 10$ for presentation reasons. 


\begin{tabular}{|c|c|c|c|c|}
\hline sector & production & fuel substitution & energy intensity & sector composition \\
\hline \multicolumn{5}{|c|}{ A) aggregate results (Figure A1, 46 sectors excluding the energy sector) } \\
\hline 1: aggregate & + & - & $\pm /-$ & - \\
\hline \multicolumn{5}{|c|}{ B) most emitting sectors (Figures A2a-A2g) } \\
\hline 2: air transport & $+($ dep. on sub-period $)$ & 0 & + & \\
\hline 3: ship transport & $+($ dep. on sub-period) & 0 & + & \\
\hline 4: land transport & $+($ dep. on sub-period $)$ & \pm & $\pm /-$ & \\
\hline 5: energy & \pm & - & \pm & \\
\hline 6: basic metals & $+($ dep. on sub-period $)$ & \pm & - & \\
\hline 7: petroleum products & $+($ dep. on sub-period $)$ & $0 /-$ & \pm & \\
\hline 8: pulp and paper & $+($ dep. on sub-period $)$ & - & - & \\
\hline \multicolumn{5}{|c|}{ C) next seven sectors (contributing between $1.5 \%$ and $5 \%$ of total emissions) } \\
\hline 9: wholes./retail trade & + & + & + & \\
\hline 10: construction & + (dep. on sub-period) & \pm & \pm & \\
\hline 11: non-metallic mineral prod. & $+($ dep. on sub-period $)$ & \pm & \pm & \\
\hline 12: chemicals & + & $\pm /+$ & - & \\
\hline 13: food/beverage/tobacco & $+($ dep. on sub-period $)$ & $\pm /-$ & - & \\
\hline 14: forestry & $\pm /+$ & $0 /+$ & + & \\
\hline 15: agriculture & $+($ dep. on sub-period $)$ & $\pm /-$ & $\pm /-$ & \\
\hline
\end{tabular}

Table 2: Results from the decomposition analysis (contributions to changes in emissions from changes in production, fuel substitution, energy intensity and sectoral change; cf. the figures A1, A2a-A2g for further illustration; "+" means "contributes to increasing emissions", i.e. in most years, a clear positive effect can be identified; "-" means "contributes to decreasing emissions", i.e. in most years, a clear negative effect can be identified; " \pm " means that there is no definite overall positive or negative effect, but for most individual years, the effect is clearly positive or negative; "0" means "no effect", i.e. there is a very small or zero effect in most individual years; "dep. on sub-period" means that there are large differences in the effects between different sub-periods; as an exapmle: for some sub-periods, the effects are clearly positive, while for others, no effect can be identified; the combined signs of indeterminate judgements $( \pm$ or 0$)$ with clear trend judgements $(+$ or -) indicate the presence of a slight 3 tfend in the indeterminate judgement) 


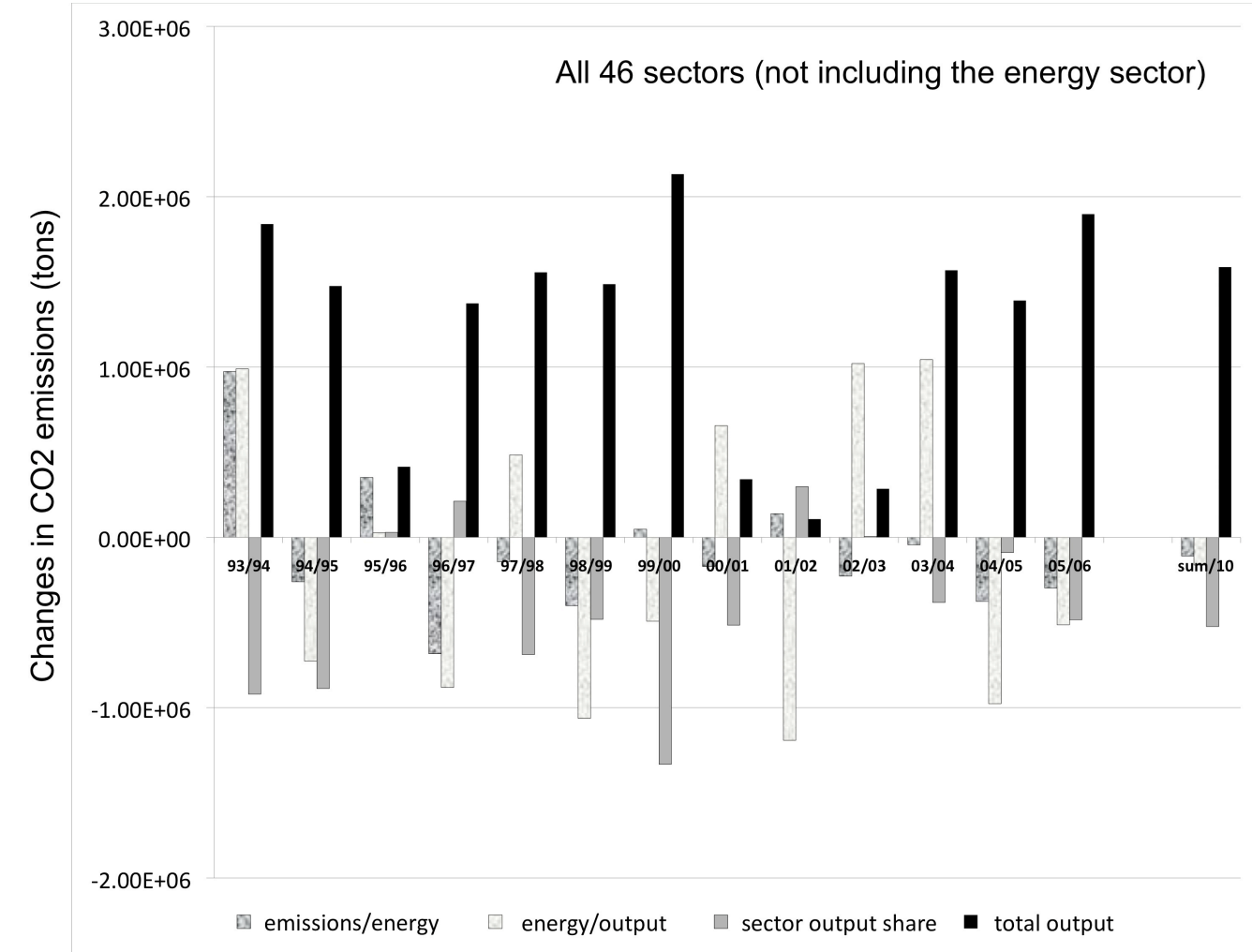

Figure A1: Decomposition results: aggregate analysis (46 sectors excluding the energy sector) 


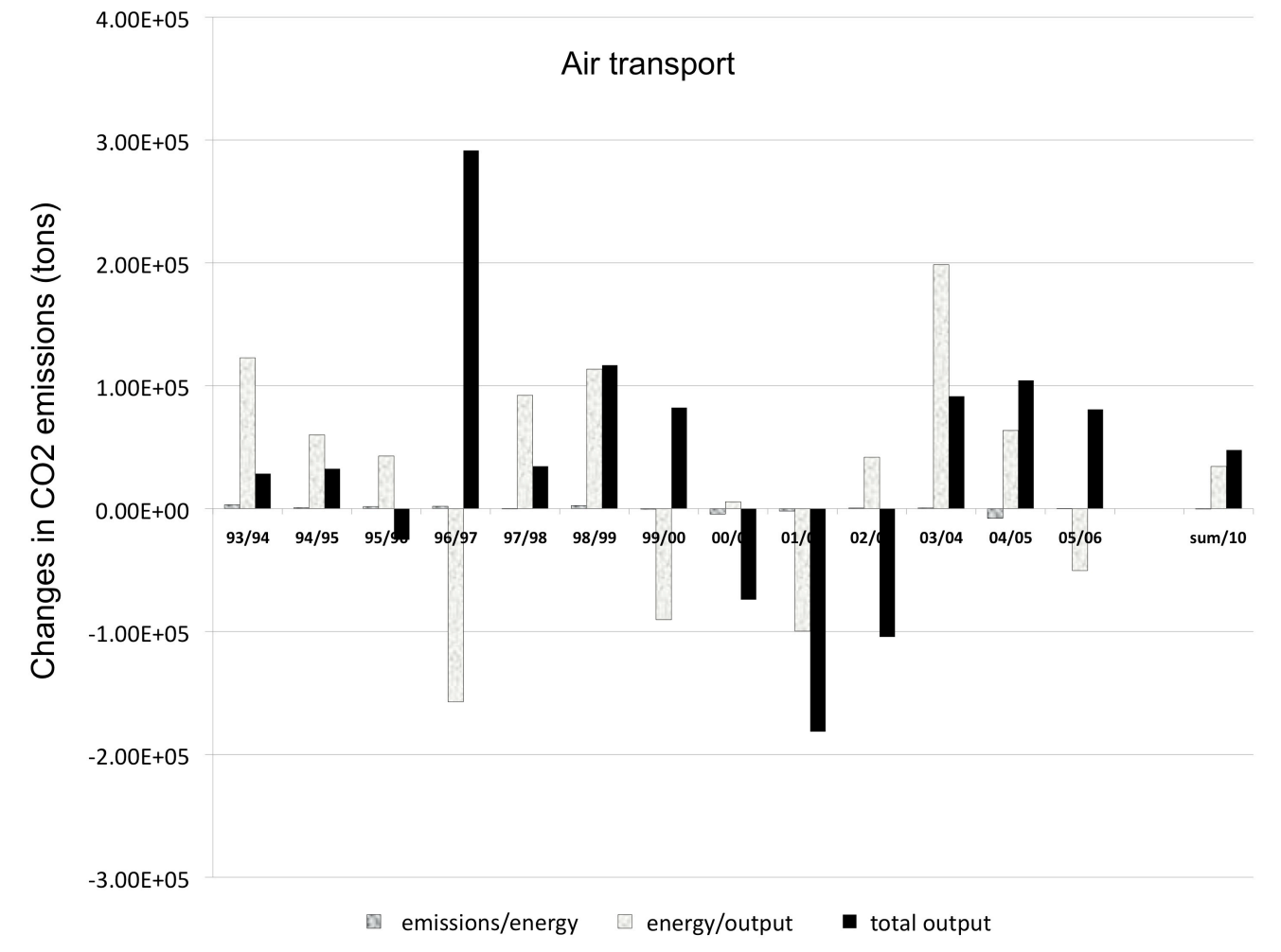

Figure A2a: Decomposition results: air transport 


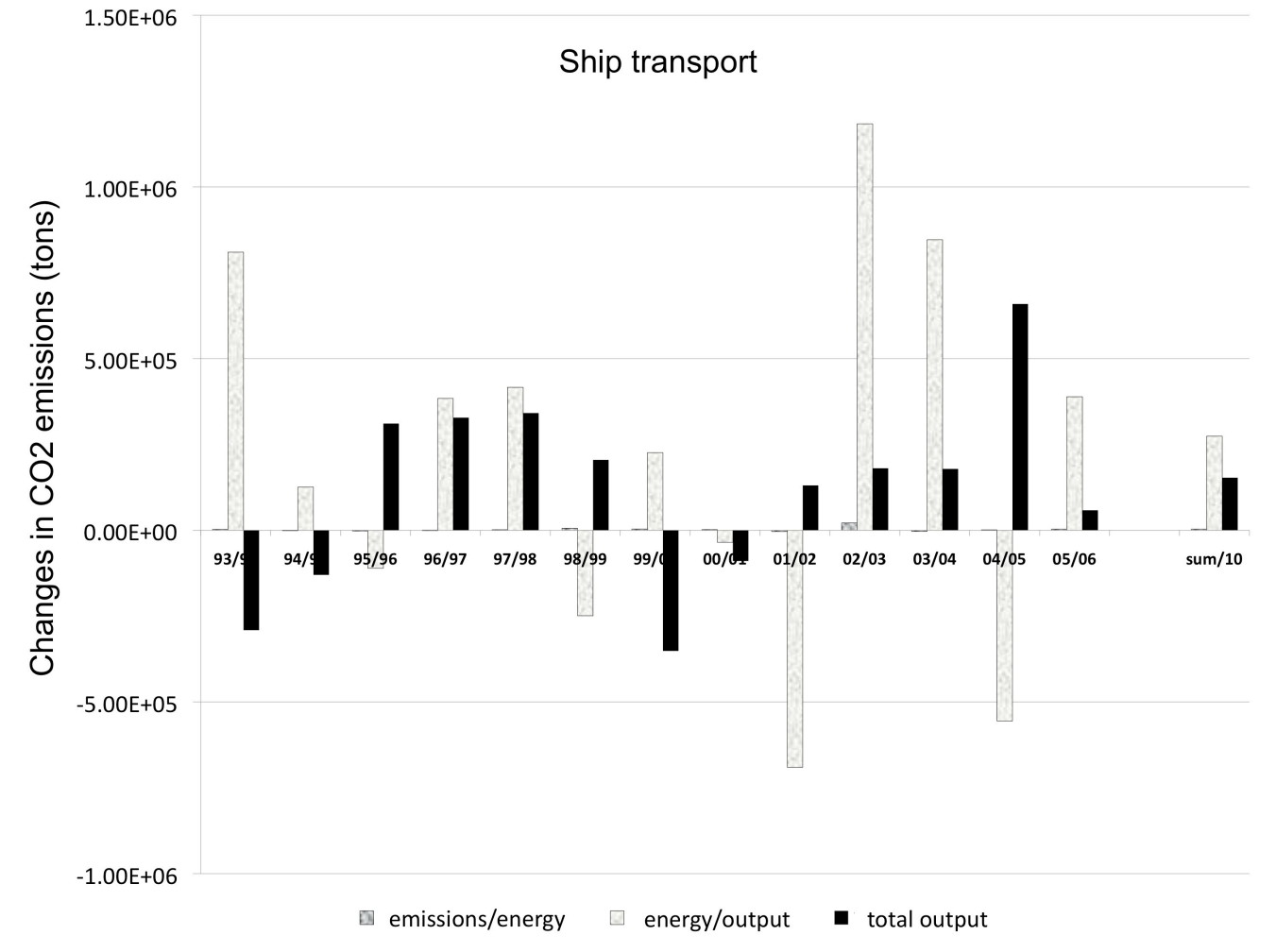

Figure A2b: Decomposition results: ship transport 


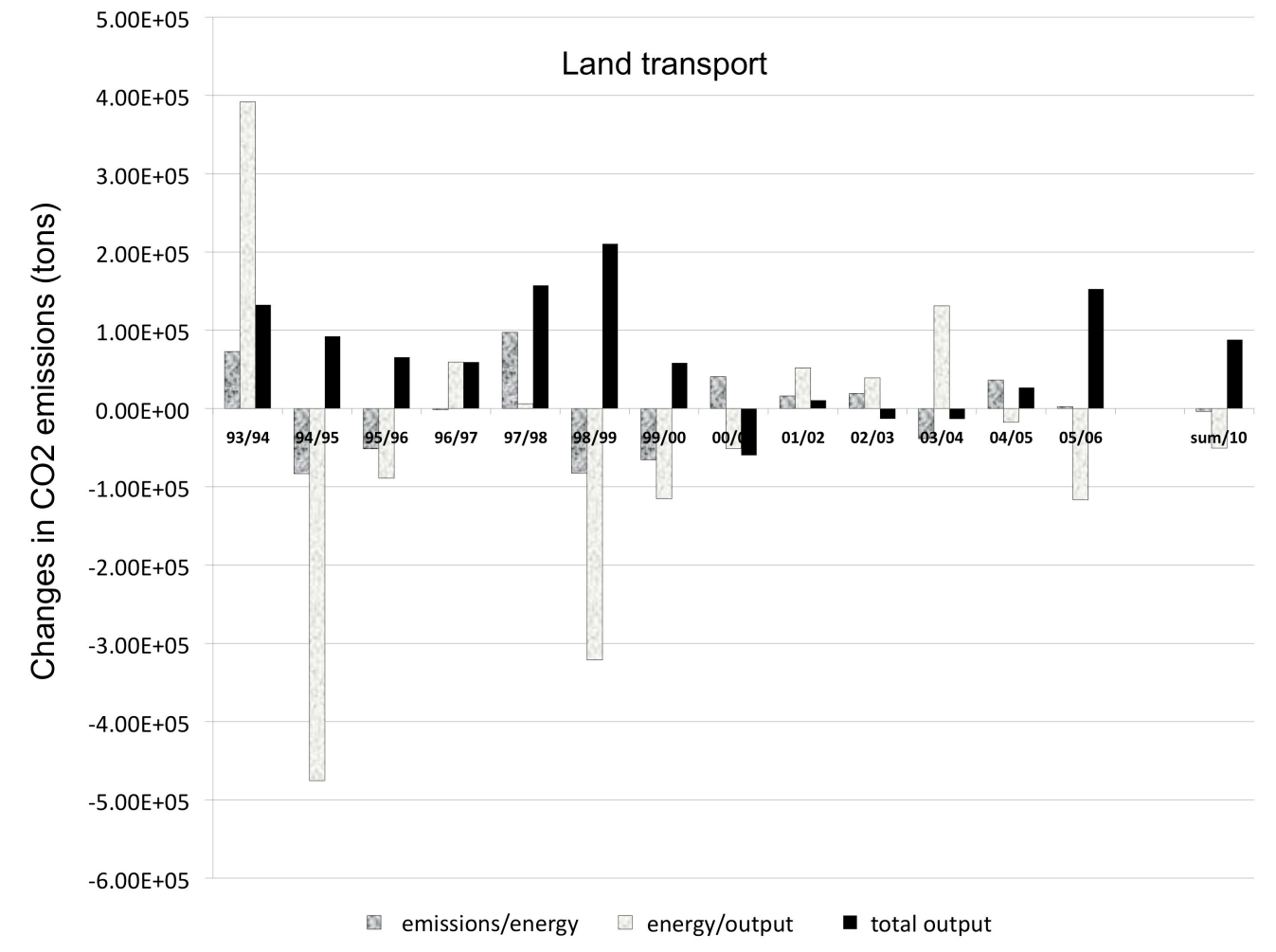

Figure A2c: Decomposition results: land transport 


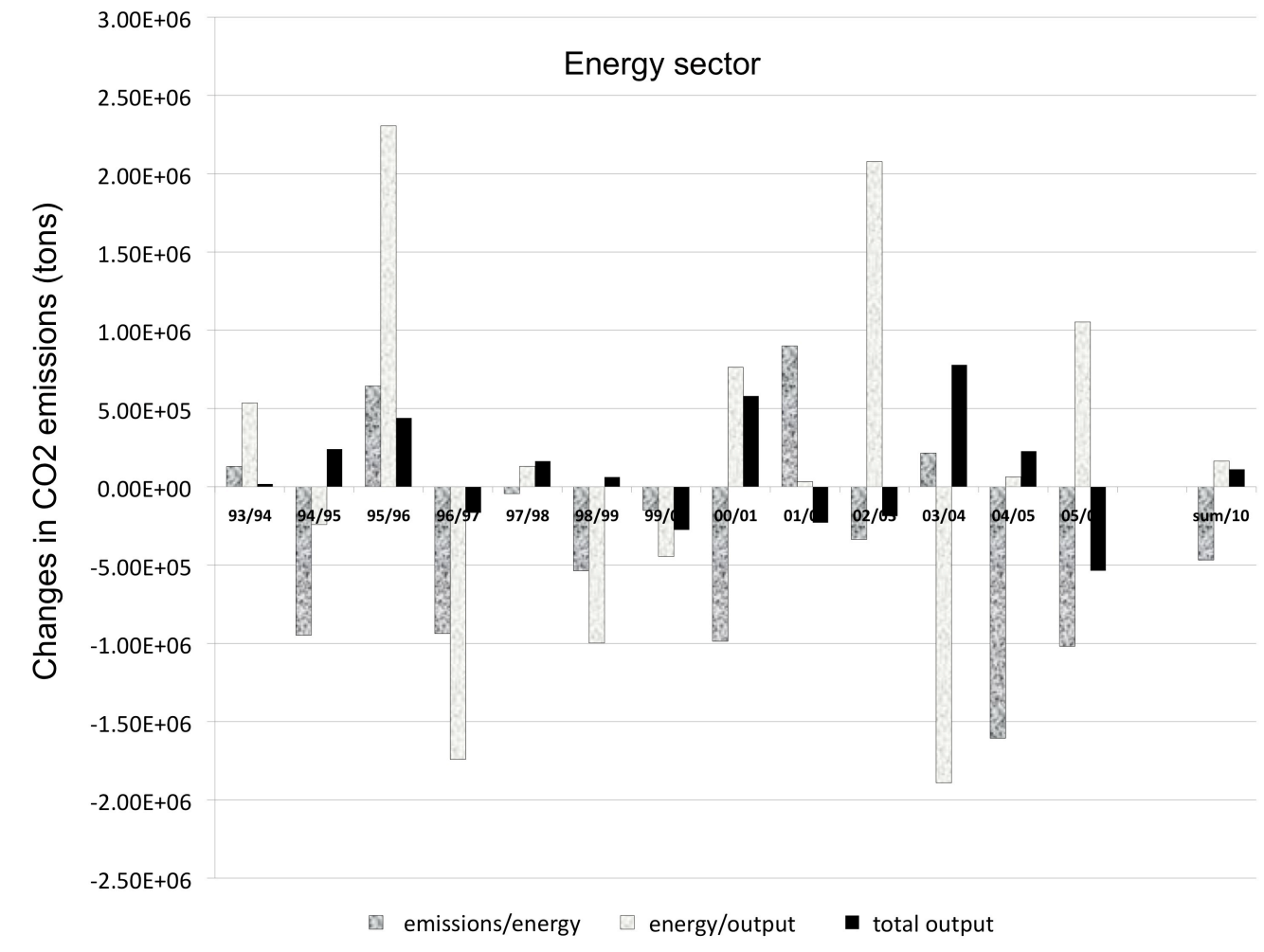

Figure A2d: Decomposition results: energy 


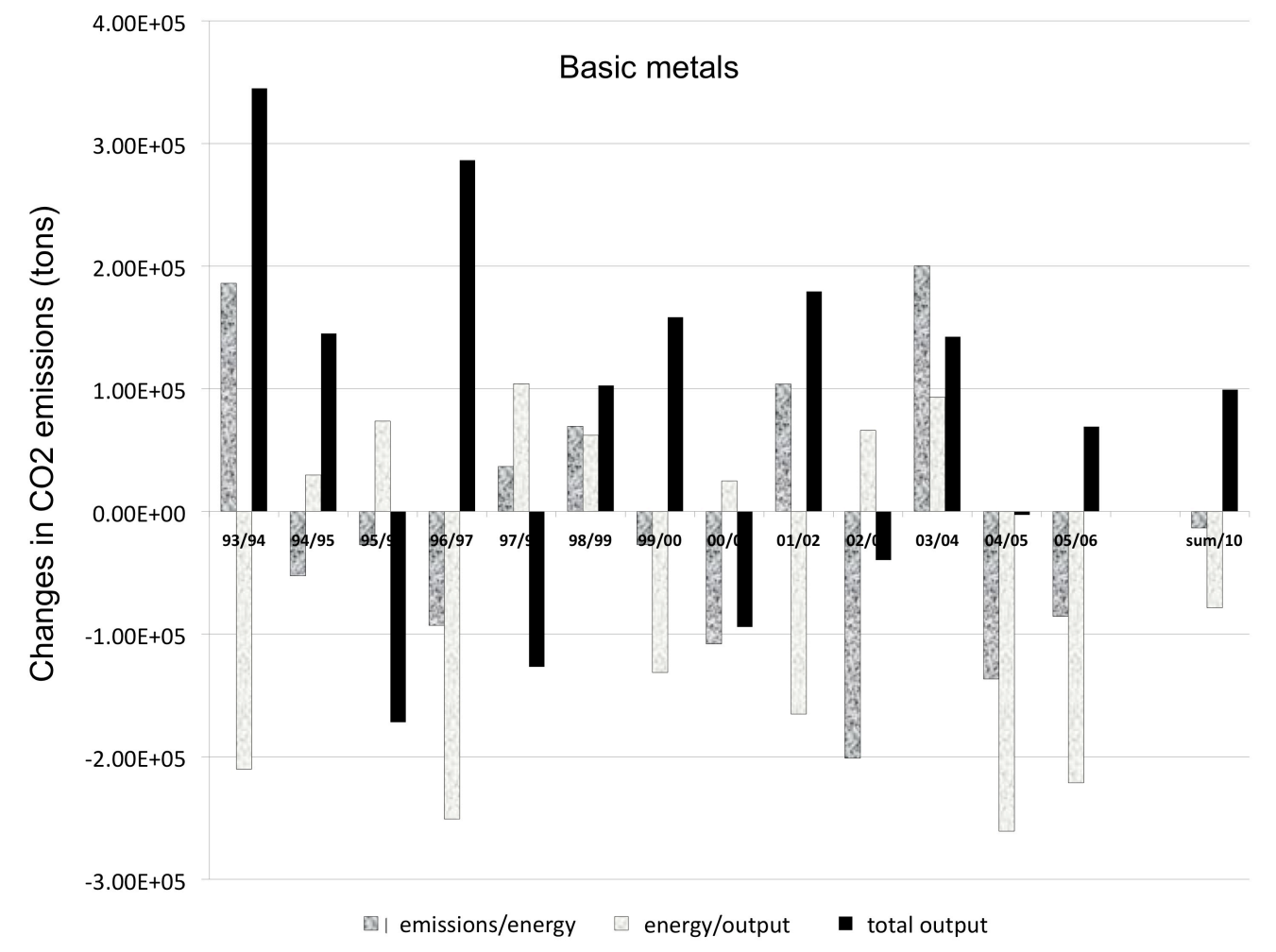

Figure A2e: Decomposition results: basic metals industry 


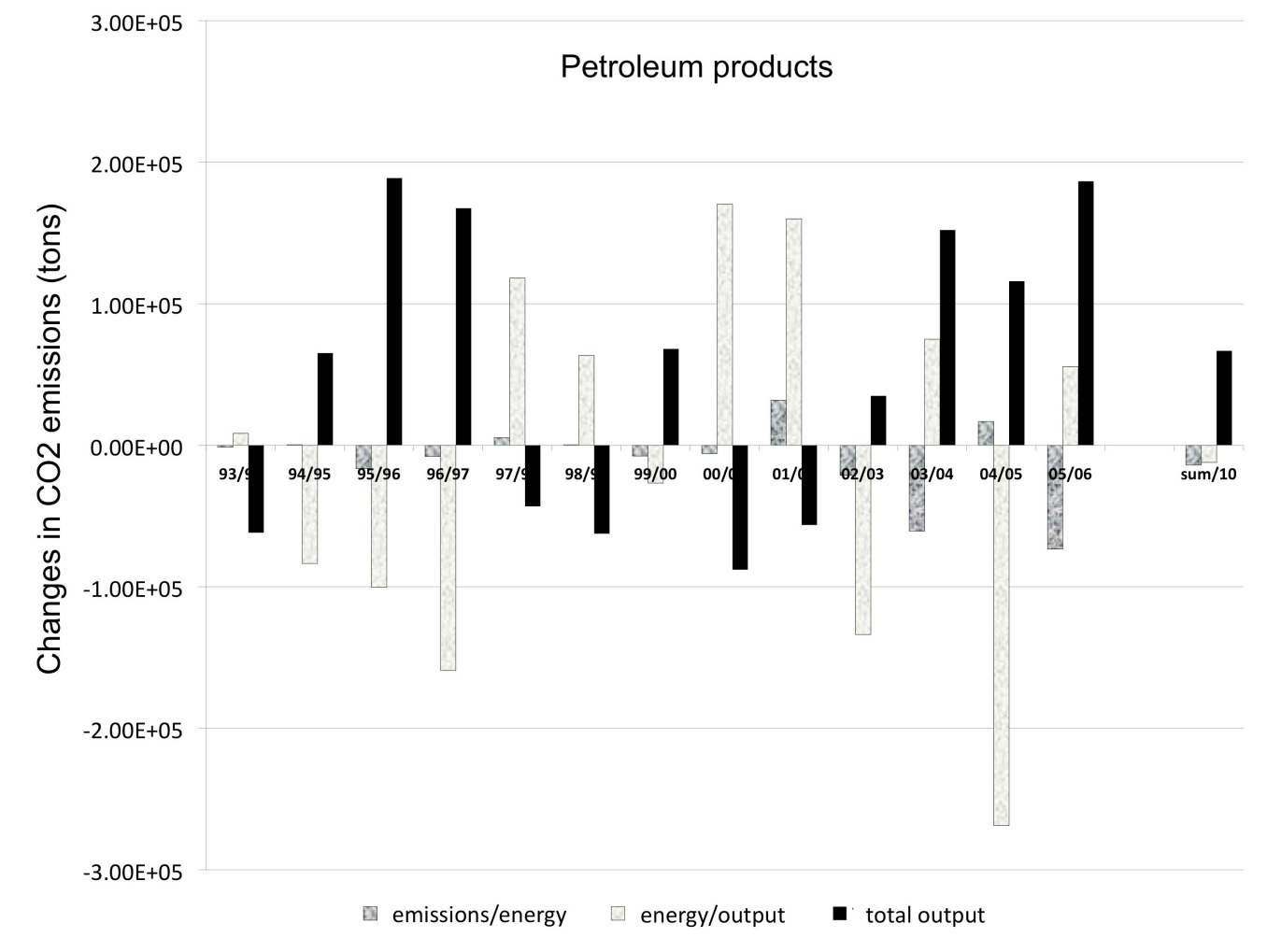

Figure A2f: Decomposition results: petroleum products 


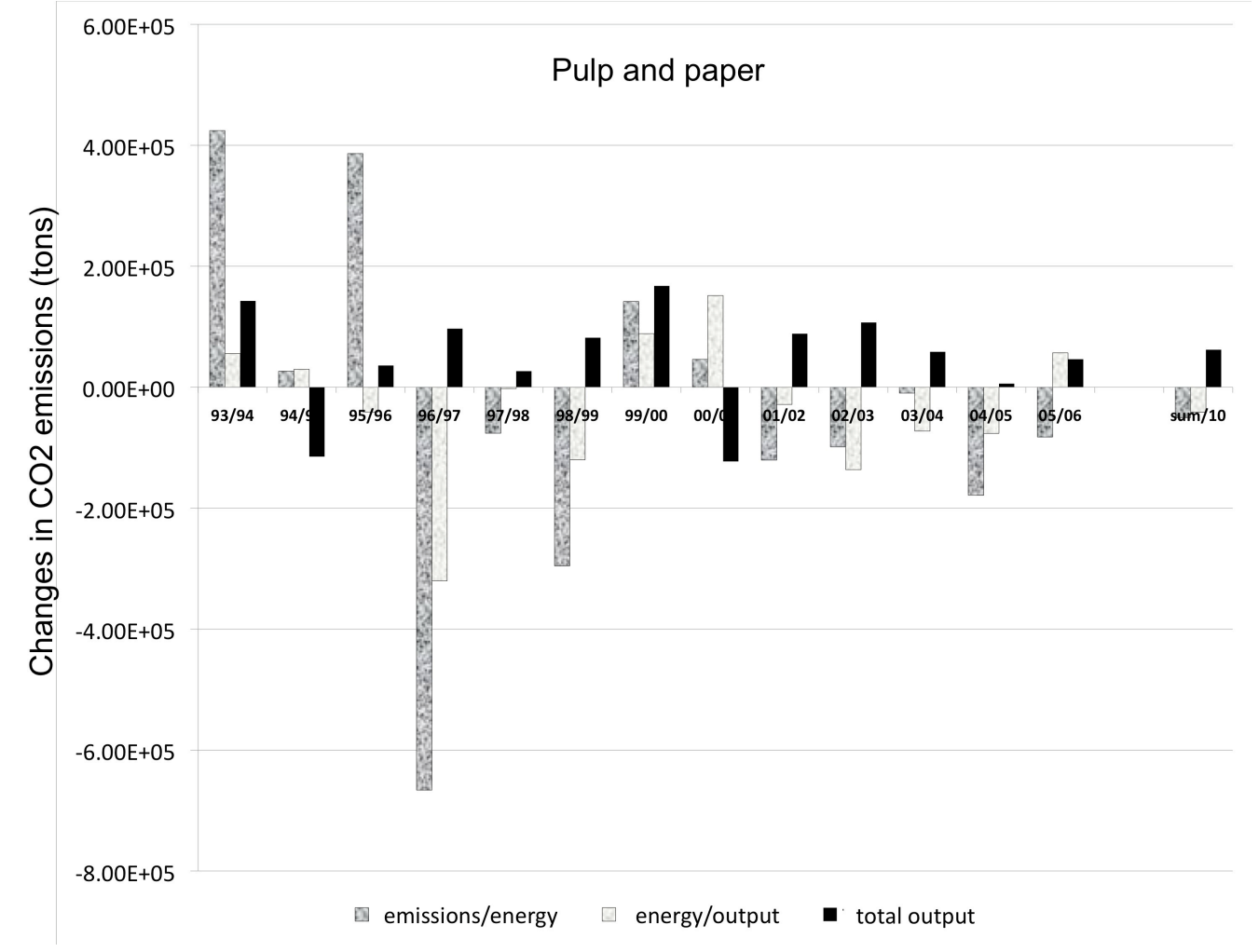

Figure A2g: Decomposition results: pulp and paper 